\title{
Korogocho Slum Upgrading Programme
}

IFRA Nairobi

\section{(2) OpenEdition}

\section{Journals}

Electronic version

URL: https://journals.openedition.org/eastafrica/541

DOI: $10.4000 /$ eastafrica.541

ISSN: 2790-1076

\section{Publisher}

IFRA - Institut Français de Recherche en Afrique

\section{Printed version}

Date of publication: 1 September 2011

Number of pages: 159-166

ISSN: 2071-7245

\section{Electronic reference}

IFRA Nairobi, "Korogocho Slum Upgrading Programme", Les Cahiers d'Afrique de l'Est / The East African Review [Online], 44 | 2011, Online since 07 May 2019, connection on 09 December 2021. URL: http:// journals.openedition.org/eastafrica/541 ; DOI: https://doi.org/10.4000/eastafrica.541

This text was automatically generated on 9 December 2021.

Les Cahiers d'Afrique de l'Est / The East African Review 


\title{
Korogocho Slum Upgrading Programme
}

\author{
IFRA Nairobi
}

\section{Introduction}

1 The Korogocho Slum Upgrading Programme is a joint initiative of the Government of Kenya with funding support from the Government of Italy through a debt-fordevelopment swap entered into by the two governments in 2008. Korogocho slum is one of the largest slums in Nairobi, located in Kasarani District, with an estimated population of about 34,152 people on approximately 50 hectares of land owned by the Government of Kenya (Ministry of Local Government [MOLG], 2010). Korogocho is composed of eight villages: Korogocho A, Korogocho B, Grogan A, Grogan B, Nyayo, Gitathuru, Kisumu Ndogo and Highridge (Figure 1). It borders the largest dumping site in Nairobi i.e. Dandora.

2 Korogocho settlement started in the 1960s and grew in the 1970s as inhabitants were settled from other slums demolished in other parts of Nairobi. It is characterised by high poverty rates, crime and unemployment. There is also limited access to basic services and infrastructure like water, sanitation, access roads, electricity, educational and health facilities. The housing structures in Korogocho are constructed from recycled materials such as corrugated iron sheets, timber, mud and natural stone. 
Figure 1: Map of Korogocho Area

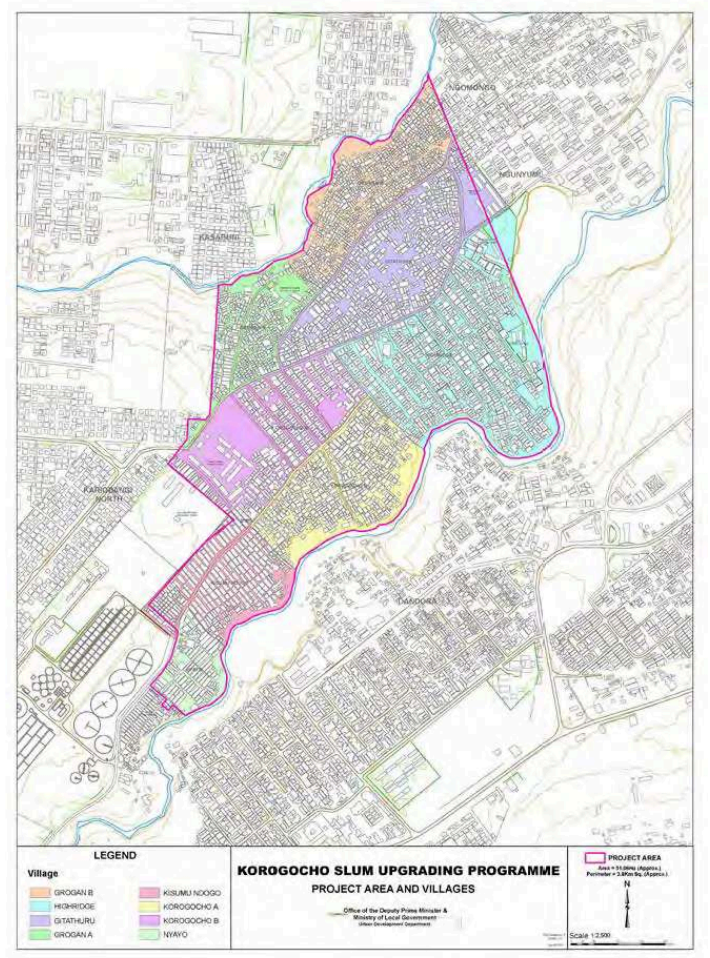

Source: Ministry of Local Government (2009)

\section{Goals of the Korogocho Slum Upgrading Programme}

3 The long-term goal of the Korogocho Slum Upgrading Programme is to improve the lives of slum-dwellers in line with the Millennium Development Goals (MDGs). The programme's objectives are to:

- Undertake a situational analysis of Korogocho;

- Prepare a Sustainable Integrated Plan (SIP) for Korogocho;

- Build the capacity of various actors/institutions;

- Provide collective security of tenure to the residents of Korogocho;

- Ensure improvement of the slum upgrading programme for visible impact.

\section{Programme Design and Implementation}

This programme is coordinated by the Ministry of Local Government (MOLG) as the lead executing agency through the Programme Management Unit (PMU). The other lead agencies involved in this project are the Ministry of Lands (MOL), the City Council of Nairobi and the United Nations Human Settlements Programme (UN-HABITAT) which form the Technical Working Groups. The Programme has two key committees that oversee its implementation. 


\section{Residents Committee (RC)}

5 The Residents Committee (RC) of Korogocho was formed in August 2008 and is composed of six elected representatives from each of the eight villages in Korogocho, with the area councilor and area chief being ex-officials. This committee represents the residents in the programme and they also sensitize the community to participate in the ongoing slum upgrading activities. The RC also gives and receives feedback from the community with regard to key issues about the programme while also resolving disputes at the local level. The committee implements its activities by undertaking various meetings and workshops among themselves and with programme officials. They also hold community barazas (public meetings) with the residents to transmit information directly to the community and also get feedback which they relay to the programme officials.

6 The committee faces various challenges in undertaking their work including having to accommodate the diverse views of the 48 committee members who represent various groups like tenants, structure owners, the youth, women and elderly people. They also do this work voluntarily, meaning that they have to leave their daily chores to spare time for the implementation of programme activities.

\section{Steering Committee (SC)}

7 The Steering Committee (SC) of Korogocho gives guidance to the upgrading programme. It is composed of representatives from the Ministries of: Finance, Local Government, Lands and Housing. This SC also has representation from the Provincial Administration, the City Council of Nairobi, the RC, Faith Based Organisations (FBOs), the Italian Cooperation and UN-HABITAT.

8 The SC, which meets monthly, approves work plans, receives progress reports from lead agencies, ensures that programme activities are on course and monitors utilization of funds. The presence of the Korogocho residents in this committee, through the RC, enables them to participate at the very top level decision making organ of the programme, ensuring community views are well presented in the implementation process.

\section{Results and Impact}

9 The programme implementation started with consultative meetings between opinion leaders from the community, FBOs and Government officials. This preparatory stage was very important in setting a good foundation for the programme as the community leaders were taken through the objectives of the programme. This culminated in the formation of the RC, elected democratically by the residents of Korogocho. The election of the RC was supervised by officials from the MOLG and the Provincial Administration to ensure that the exercise was carried out transparently to the satisfaction of the residents.

A comprehensive situational analysis has been undertaken that includes preparation of base maps from recent aerial photographs, mapping of all structures in the settlement, enumeration of all residents and a comprehensive socio-economic survey. 


\section{Base Map Preparation}

11 Using the latest aerial photographs, the digitising of all structures using Geographical Information Systems (GIS) was undertaken. The draft base maps were then verified by the RC, who defined the Programme's project area and the boundaries of each of the eight villages in Korogocho.

\section{Structure Numbering}

12 A joint team from the MOLG, MOL and the RC undertook the exercise of identifying every structure in the base maps and the structure owners. This was to ensure that the final base map was up to date and accurate. The process also included provision of a structure number and recording of structure owner details. The information was then updated on the base map and presented to the residents committee for verification.

\section{Enumeration survey}

13 The enumeration was carried out to update the data base on the occupancy of each structure in Korogocho. The survey identified the number of occupants living in every structure, household size, the number of rooms in every structure and the year the occupant resided in the structure. The data also included identification of resident or non-resident structure owners. This survey was carried out by a team from the MOLG, MOL, UN-HABITAT and the RC.

\section{Socio-economic survey}

14 A comprehensive socio-economic survey was carried out to take stock of the existing physical, socio-economic and environmental issues in Korogocho. It was also supposed to outline the main problems facing the residents of Korogocho, and the vision of the residents of Korogocho. The survey included administering of questionnaires for households and businesses and focus group discussions. It provided both quantitative and qualitative data that was integrated in GIS to allow for interrogation of different aspects by users.

The above exercises constitute the situational analysis of Korogocho that will inform the preparation of a Sustainable Integrated Plan (SIP) of the settlement. The SIP will transform the settlement from an informal to a formal settlement and will pave way for the process of delivering an appropriate security of tenure. Sensitisation of the community on the existing land tenure options has been undertaken ahead of the planning process to ensure that they are informed of the available options. Concurrently, the programme has been implementing concrete infrastructure projects in the informal settlement that have included provision of water tanks, construction of a foot bridge and tarmacking of roads (Figure 2). While these projects have been implemented through qualified contractors, the programme has ensured that the projects make use of the available unskilled labour in the community. These projects have increased accessibility in the area, increased business opportunities and reduced incidences of crime. 
The concurrent rehabilitation of infrastructure with the other activities has boosted the community's confidence as it has achieved concrete and visible interventions that made them believe that the upgrading programme was real. This has encouraged the community to participate in other programme activities like enumeration and the socio-economic survey. The rehabilitation of infrastructure, particularly the road, led to the relocation of residents from the road reserves. The RC facilitated this relocation, by identifying various open spaces within the settlement where these residents could be relocated to. The importance of the community representatives was evident in this exercise in ensuring that it was carried out voluntarily and peacefully inasmuch as the construction activities were slowed down by the high human traffic in the settlement, especially at the Soko Mjinga market.

Figure 2: Map of Korogocho Roads

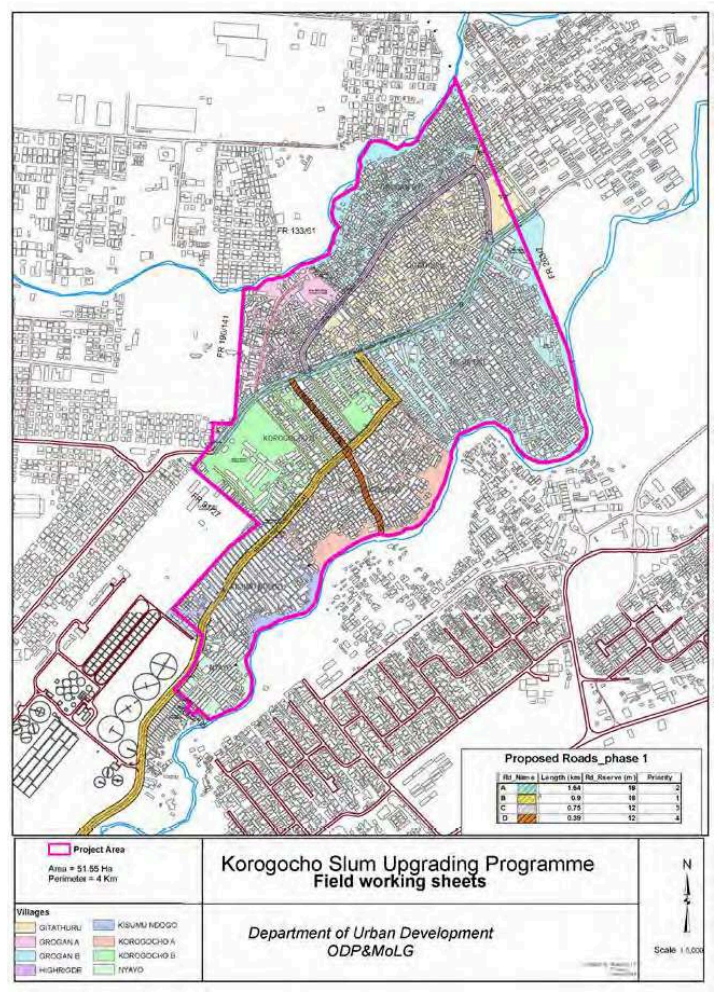

Source: Ministry of Local Government (2009)

\section{Key Challenges}

The first key challenge in the implementation of the Korogocho programme is managing the participation of the community. This is because the community has diverse interest groups ranging from youth groups, FBOs, Community Based Organisations (CBOs), "landlords," structure owners, residents, with divergent views and interests. Moreover, there is polarisation of the community along ethnic and religious lines, requiring efforts to ensure that the community speaks with one voice.

A second challenge the programme has faced is scepticism due to past failed attempts to upgrade the slum. At the inception of the programme, the residents took time to engage the partners to avoid mistrust. Nevertheless, the residents showed a lot of 
confidence with the government as they were optimistic that the government would adequately resolve the land tenure issue.

Third, difficulties are experienced in information dissemination. While the programme sensitises the residents on related activities through community barazas, rumours do arise occasionally creating confusion among the residents. When distorted information touches on sensitive issues such as security of tenure, tensions arise among the residents.

\section{BIBLIOGRAPHY}

Government of Kenya, Ministry of Local Government [MOLG]. 2009a. Map of Korogocho Area.

Government of Kenya, Ministry of Local Government [MOLG]. 2009b. Map of Korogocho Roads.

Government of Kenya. 2010. Ministry of Local Government Enumeration Survey.

\section{ABSTRACTS}

This article presents certain aspects of the Korogocho slum upgrading programme in Kasarani, Nairobi. It focuses on the goals, design, implementation and impact of this programme while presenting some of the key challenges that have been faced in the implementation process.

INDEX

Geographical index: Kenya 